\title{
Diabetic Feet Scald with Popliteal Artery Ligation - A New Study Rat Model, Represent Human Diabetic Foot Ulceration
}

\author{
Yandong Liu ${ }^{1}$, Huimin Han ${ }^{1 *}$, Abu Taiub Mohammed Mohiuddin Chowdhury ${ }^{2}$ and Shahid Alam ${ }^{3}$ \\ ${ }^{1}$ Institute of Endocrinology, The $4^{\text {th }}$ Daqing City Hospital, Daqing, China \\ ${ }^{2}$ Department of Digestive disease-II, First Affiliated Hospital of Jiamusi University, China \\ ${ }^{3}$ Department of Vascular Surgery, First Affiliated Hospital of Jiamusi University, China
}

*Corresponding author: Huimin Han, Institute of Endocrinology, The 4th Daqing City Hospital, Daqing, China, Tel: 008801817711079; E-mail: lyn2799@126.com.cn

Edited and prepared by: Abu Taiub Mohammed Mohiuddin Chowdhury, Department of Digestive Disease-II, The 1st affiliated Hospital of Jiamusi University, Jiamusi, Heilongjiang, P.R. China, E-mail: dr_mohiuddinchy@yahoo.com

Received date: December 04, 2014, Accepted date: December 18, 2014, Published date: December 26, 2014

Copyright: $\odot 2014 \mathrm{Han} \mathrm{H}$, et al. This is an open-access article distributed under the terms of the Creative Commons Attribution License, which permits unrestricted use, distribution, and reproduction in any medium, provided the original author(s) and source are credited.

\begin{abstract}
Diabetes mellitus is a potent metabolic disorder of this time. Due to the progression of disease itself and along with the collateral damages by its various complications this is being considered as one of the greatest threat to patient's well-being \& status. During recent years the prevalence of ulceration in diabetic patients especially foot ulcer has dramatically increased, causing tremendous negative impact over the patient. But unfortunately, there is no reliable animal model that resembles human diabetic foot ulcer, thus the study of ulcer healing under conditions of "diabetes mellitus" remains a challenge. In this literature, we describe a new approach to establish an experimental model that accurately resembles human diabetic foot ulceration. This new model will likely provide a superior way to study diabetic foot ulceration. The objective of this study was aimed to investigate and compare the established "rat models of diabetic foot ulceration" in order to determine the most suitable option that represents the similar state of the disease in human. Diabetic sample were prepared by using Wistar rats and they were divided in to four groups - A. Diabetic foot scalded group, B. bilateral popliteal artery ligation group, C. Diabetic foot scalded plus popliteal artery ligation group, D. Disease control group. After a period of thirty days the rats were assessed bynail discoloration, degree of muscular atrophy, size of ulcer, purulent secretions and presence granulation tissue in the wound bed. Our study concludes that- "diabetic foot scalded plus popliteal artery ligation group" rats most closely resemble the symptoms of the human diabetic foot.
\end{abstract}

Keywords: Diabetic foot; Diabetic foot rat; Scalding; Bilateral popliteal artery ligation; Human diabetic foot; Diabetes related foot disorders

\section{Introduction}

Diabetes mellitus is a slow progressing, long-term \& painful condition associated with high incidence of amputation. As the disease progress it creates a dramatic negative impact on patients' well-being, socio economic condition and psychological state. As a result physicians, scientists from various specialties including basic medical departments have been increasingly involved in this area of research. Unfortunately there is no established reliable animal model that resembles human diabetic foot ulcer. Thus the study of ulcer healing under conditions of "diabetes mellitus" remains incomplete. Till now several models have been reported in the literature generated by vastly different techniques (such as foot pad scalding or artery ligation). However important factors like early death due to hyperglycemia (Within 48 hours modeling), dehydration, electrolyte disorder and infection etc must not be ignored. All the currently available models of foot ulcer represent acute disease including acute lower limb ischemia model, acute lower limb ulcer model and acute lower limb neurological ulcer model. So it is crucial to improve the survival rate of diabetic animals before a model is successfully established. In this manuscript, we report a new approach to establish an experimental model that accurately resembles human diabetic foot ulceration and will likely provide a superior way to study human diabetic foot.

\section{Materials and Methods}

\section{Reagents and drugs}

Streptozotocin (STZ) (Islet beta-cell toxin, from Sigma, USA); Male Wistar rats (Prepared by the Centre of Experimental Animals at the Heilongjiang Chinese Medicine University, China); Blood glucose measurement device (From Abbott S.A. USA); Injection Humulin70/30 insulin from Lilly France S.A.S.

\section{Animal models}

To establish a proper study model of diabetic foot rats we choose fifty-five healthy male Wistar rats weight about $180 \pm 20 \mathrm{~g}$. They were properly feed (Ad libitum) and kept under a $12 \mathrm{~h}$ of alternate light \& dark cycle for a week before STZ injection. All the rats were administered an intra-peritoneal single dose of $55 \mathrm{mg} / \mathrm{kg} \mathrm{STZ}$ (dissolved in $0.1 \mathrm{M}$ sodium citrate buffer $\mathrm{pH}=4.2$ ) [1,2], following 10 hours of fasting. After Forty-eight hours, blood glucose assessments were done by collecting sample from tail vein. Rats presented with blood glucose level of $>16.7 \mathrm{mmol} /$ lit at least twice were considered as successful diabetic models. Specific amounts of sodium, potassium, chloride and magnesium $\left(\mathrm{Na}^{+}, \mathrm{K}^{+}, \mathrm{Cl}^{-}, \mathrm{Mg}^{2+}\right)$ were added to the drinking water $\left(\mathrm{NaCl} 2.25 \mathrm{gm}, \mathrm{KCl} 1 \mathrm{gm}, \mathrm{MgSO}_{4} 1 \mathrm{gm}\right.$ in $500 \mathrm{ml}$ of drinking water). To prevent acute complications and to achieve the maximum life time in diabetic rats mixed acting insulin (Humulin70/30 2u-12u/rat, average $3.4 \mathrm{u} / \mathrm{rat}$ ) was administered to 
Citation: Han H, Liu Y, Chowdhury ATMM, Alam S (2015) Diabetic Feet Scald with Popliteal Artery Ligation - A New Study Rat Model, Represent

maintain the blood glucose level in between $20-25 \mathrm{mmol} / \mathrm{lit}$, which was monitored in a daily routine.

At six months post-STZ injection Experimental animals were randomly divided into four groups: Foot scalded group $(\mathrm{n}=15$, group A), Bilateral popliteal artery ligation group ( $\mathrm{n}=15$, group B), Foot scalded plus artery ligation group $(n=15$, group $C)$ and Disease control group ( $\mathrm{n}=10$, group $\mathrm{D})$.

With aseptic precaution, under microscopy bilateral popliteal artery ligation was performed in group B and group C Rats. One month later rats in group A and group $\mathrm{C}$ were scalded by a cylindrical steel rod ( $9 \mathrm{~mm}$ in diameter which was heated in boiling water for more than 10 minutes). The steel rod was placed into close contact on the plantar skin of rats for 25 seconds without applying pressure. The resultant wounds were bandaged with sterilized gauze. These were replaced after every two days interval and observed for 30 days.

\section{Measurements of disease parameters}

Each of the Rats was closely assessed for:

- Nail discoloration of the limbs in all rats.

- Degree of muscular atrophy in all groups.

- Change in size of ulcer in group-A and group-C.

- Purulent secretions from the wound / ulcer in group-A and group-C.

- Appearance of granulation tissue in the wound bed / healing.

\section{Statistics}

All measurable data were calculated as mean \pm standard deviation () and the difference between the groups were compared by using t-test. All qualitative data were analyzed by $\mathrm{X} 2$ test. Statistical significance was defined at $\mathrm{P}<0.05$ in all analysis.

\section{Results}

\section{Comparison of ulcer size in each group}

The resulting ulcers were larger in group $\mathrm{C}(5.8 \pm 1.2 \mathrm{~mm})$ than in group A $(4.4 \pm 1.3 \mathrm{~mm})(\mathrm{P}<0.01)$, indicating that the arterial ligation procedure functionally augmented the scalding technique (Figures $1-5)$.

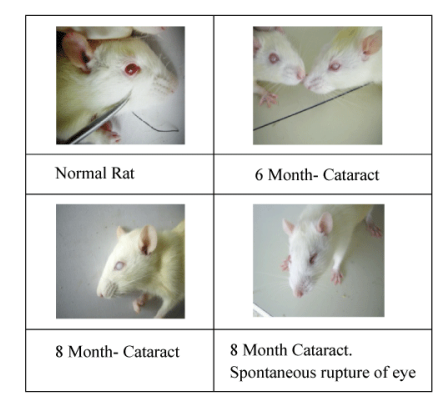

Figure 1: Changes of Eye in Study model (Rats)

\section{Purulent secretions}

Purulent secretion were seen in twelve rats (80\%) in Group C. Compared with Group A has statistically significant difference $(\mathrm{P}<0.05)$ as showed in Table 1.

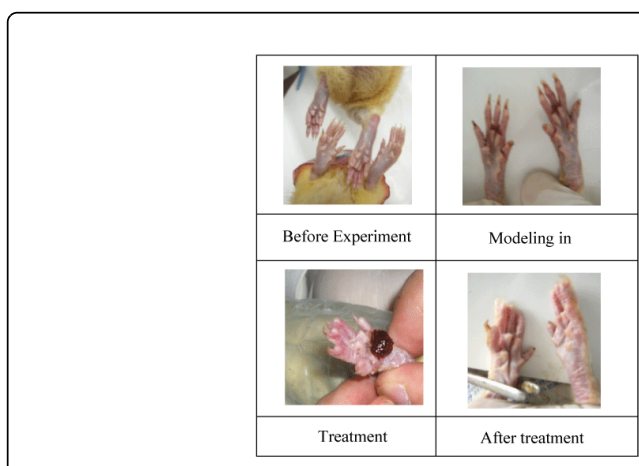

Figure 2: Control group

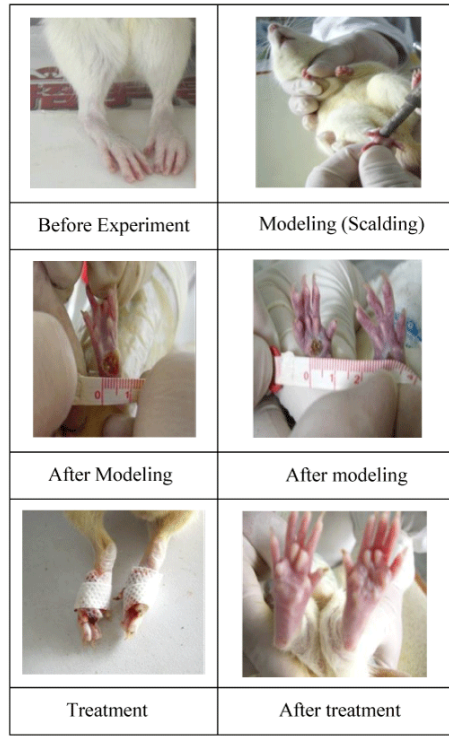

Figure 3: Foot Scald group

\begin{tabular}{|l|l|l|l|}
\hline \multirow{2}{*}{ Group } & \multicolumn{2}{|l|}{ Purulent secretions } & \multirow{2}{*}{ Totals } \\
\cline { 2 - 3 } & Yes & No & \multirow{2}{*}{} \\
\hline A & 5 & 10 & 15 \\
\hline C & 12 & 3 & 15 \\
\hline Totals & 17 & 13 & 30 \\
\hline
\end{tabular}

Table 1: Comparison of purulent secretions

12 study rat models of group $\mathrm{C}$ presented with purulent discharge. Compare to group A

The statistical difference is significant $\mathrm{P}<0.05$ (Table 1). 
Citation: Han H, Liu Y, Chowdhury ATMM, Alam S (2015) Diabetic Feet Scald with Popliteal Artery Ligation - A New Study Rat Model, Represent Human Diabetic Foot Ulceration. J Mol Genet Med 9: 149. doi:10.4172/1747-0862.1000149

Page 3 of 5

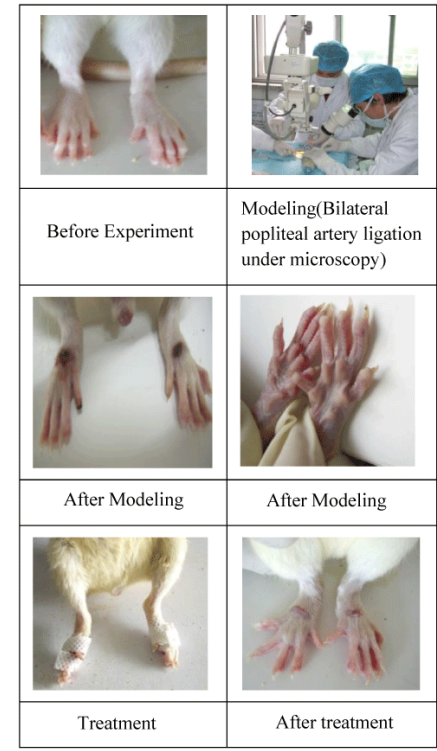

Figure 4: Bilateral lower end of the popliteal artery ligation group.

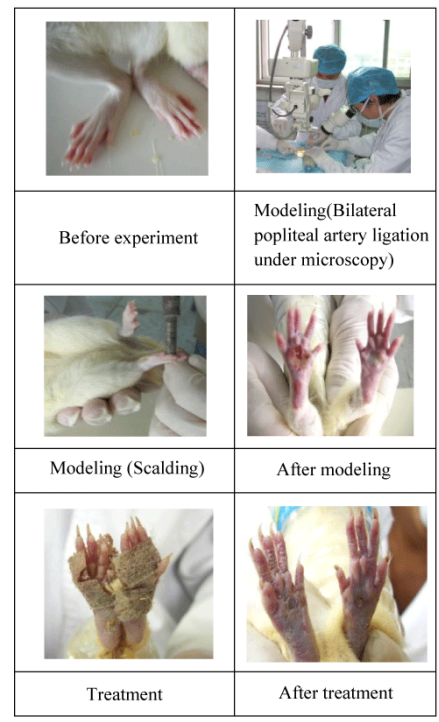

Figure 5: Bilateral lower end of the popliteal artery ligation with Scalding group.

\section{Granulation in the wound bed}

In group $\mathrm{C}$ presence of grey granulation tissue over the wound bed were detected in ten rats (66.7\%), whereas only three rats $(20 \%)$ had grey granulation in group A. These results indicated an obvious difference between the two groups $\mathrm{P}<0.05$ (Table 2).

\begin{tabular}{|l|l|l|l|}
\hline \multirow{2}{*}{ Group } & \multicolumn{2}{|l|}{ Granulation } & Totals \\
\cline { 2 - 4 } & Grey granulation & Fresh & \\
\hline
\end{tabular}

\begin{tabular}{|l|l|l|l|}
\hline A & 3 & 12 & 15 \\
\hline C & 10 & 5 & 15 \\
\hline Totals & 13 & 17 & 30 \\
\hline
\end{tabular}

Table 2: Comparison of wound granulation

Presence of gray granulation tissue in the wound bed in group C (bilateral popliteal artery ligation plus foot scald) is more than in group A (simple foot scald). This difference was statistically significant $(\mathrm{P}<0.05)$.

\section{Changes in nail color}

As showed in Table 3 among the study model, 10 rats (66.7\%) in group B and 12 rats (80\%) in group C exhibiting black discoloration of nails, whereas only four rats (26.7\%) in group A presented with such discoloration. Percentages for groups $\mathrm{B}$ and $\mathrm{C}$ were significantly higher than that of group A $(\mathrm{P}<0.01)$.

\begin{tabular}{|l|l|l|l|}
\hline \multirow{2}{*}{ Group } & \multicolumn{2}{|l|}{ Color of nail } & Totals \\
\cline { 2 - 4 } & Black & Normal & \\
\hline A & 4 & 11 & 15 \\
\hline B & 10 & 5 & 15 \\
\hline C & 12 & 3 & 15 \\
\hline D & 2 & 8 & 10 \\
\hline Totals & 28 & 27 & 55 \\
\hline
\end{tabular}

Table 3: Comparison of nail color

Black discoloration of nail in group B (bilateral popliteal artery ligation group) and group C (bilateral popliteal artery ligation plus foot scald) is more significant in comparison to other groups. The difference was significant $(\mathrm{P}<0.01)$.

\section{Muscular atrophy}

Progressive muscular atrophy had observed in group B and group C which was compared "significant" with group A $(\mathrm{P}<0.05)$. The results are showed in Table 4.

\begin{tabular}{|l|l|l|l|}
\hline \multirow{2}{*}{ Group } & \multicolumn{2}{l|}{ Muscular atrophy } & Totals \\
\cline { 2 - 3 } & Worse & Mild & \multirow{2}{*}{} \\
\hline A & 3 & 12 & 15 \\
\hline B & 8 & 7 & 15 \\
\hline C & 10 & 5 & 15 \\
\hline D & 2 & 8 & 10 \\
\hline Total & 23 & 32 & 55 \\
\hline
\end{tabular}

Table 4: Comparison of muscle atrophy

Group B (bilateral popliteal artery ligation) and group C (bilateral popliteal artery ligation plus foot scald) showed more significant 
degree of muscle atrophy, compare to group A. The difference was statistically significant $(\mathrm{P}<0.05)$.

\section{Temperature of foot by electronic thermometer}

No significant differences in foot temperature were seen in group A and group D study rat models (A: $31.4 \pm 0.5, \mathrm{D}: 31.7 \pm 0.4 ; \mathrm{P}>0.01$. In contrast, the temperatures of group A with group B (B: $29.6 \pm 0.3)$ and group $B$ with group $C(C: 29.2 \pm 0.2)$ were significantly different $(\mathrm{P}<0.01$ for both).

\section{Discussion}

The main causes of diabetic foot ulceration are known to be lower limb vasculopathy, neuropathy [3], secondary infection and scald [4]. Because of such complexity of causes, diabetic foot ulcer has been a great challenge for physicians and continuously demanding high attention by the scientists. Song shao hua [5] described a model of diabetic ulcer using York pigs where he used a pressure device which was able to apply a continuous pressure of $5 \mathrm{~kg}$ for 12 hours over the back of the study animal about $2 \mathrm{~cm}$ from the spine. The resultant Ulcers appeared after 1 week of the removal of the device. Unfortunately, this model failed to represent the pathogenesis of diabetic foot ulcer because of the inherent differences in circulation, neurological distribution, anatomy, physiology and biomechanics of the back and foot.

Chen LiQun [6] has described an STZ-induced diabetic Wistar rat model. According to their description they adjusted the environmental temperature of STZ induced rat's down to 10 from the $2^{\text {nd }}$ day onward up to $2^{\text {nd }}$ week, and then down to 6 from the $5^{\text {th }}$ day of the same week. At the end of the $3^{\text {rd }}$ week the onset of gangrene was observed on the limb of diabetic rats. But because of induced hypothermia which lasts over an extended period and causes significant discomfort, this method has become an ethical concern.

To avoid such concern Rich J [7] used female NOD mice of 20 weeks age, after the test standard of 3-5days expected blood glucose was achieved. Under anesthesia with aseptic precaution $10 \mu \mathrm{L}$ bacterial suspensions of Staphylococcus aureus were injected in the left distal plantar toe. The procedure results in diabetic infection of affected limb. This model has routinely been used to study diabetic limb infection.

In the literature described by Goss [8] six to eight weeks of SwissWebster mice were injected with STZ (in citrate buffer, $100 \mathrm{mg} / \mathrm{kg}$, twice daily for two days) to establish diabetic model. After a period of two weeks they were injected with $10 \mu \mathrm{L}$ of $1 \times 107$ units of SHN, SLN or SHN into the plantar surface of the right foot. One week later formations of ulcer were observed at the injection sites.

Additionally, Masaki [9-11] had reported a study of induced diabetes by injecting STZ (in citrate buffer) in male C57BL/6 mice (seven weeks old) for five days. Under anesthesia with aseptic precaution, the entire left superficial femoral artery and vein (just below the deep femoral arteries to the popliteal artery and vein) were legated and excised. Additionally left external iliac artery and vein with deep femoral and circumflex arteries and veins were also excised. The procedure results in formation of severe hind limb ischemia model after 10 days.

Furthermore, in their literature Ebrihiman [12] induced diabetes in mice by intraperitoneal injection of STZ. Then right femoral artery ligations were performed to produce unilateral hind limb ischemia. In another study Kale [13] used male SD rats to induce diabetes by intraperitoneal injection of STZ $(60 \mathrm{mg} / \mathrm{kg})$. To produce neurological diabetic foot ulcer model, Sixty-one days later nerves of the right limbs were resected in order to induce ulcerative gangrene where the authors exposed the sciatic nerve without any affecting the vascular integrity of the limb.

All of the above described models (with the exception of that from Kale B) represents an uncertain blood glucose level, although the vasculature and nerves were intact irrespective of chronic hyperglycemia. Generally the neurovascular complications of diabetic rats would not appear until three months onset disease.

In our study under slit lamp examination formation of overt cataract were detected in the diabetic rat models (Table 1) along with significant proportion of neurovascular pathological changes Table 2). This represents unique similarity with moderate to late stage diabetic patients. In other words, these rats possess all the necessary intrinsic factors for the human diabetes. In our model limb ischemia had been aggravated by ligation of popliteal artery while bypass circulation between the popliteal artery, femoral artery and the collateral circulations was kept intact. In human diabetic foot the distal limb arteries such as small and medium-sized vessels below the popliteal artery especially pedal dorsal artery are mostly affected by vasculopathy $[14,15]$. In short, our study model of rats closely mimics the limb ischemia in human diabetes. According to the published reports, approximately $14.5 \%$ of the total diabetic foot gangrene is caused by scaled and it is one of the important cause of amputation in patients with diabetic foot. Therefore, based on artery ligation in the first seven months, a $2^{\text {nd }}$ degree scald was achieved on the plantar skin of the hind limb of diabetic rats by a heated steel rod. These resultant wounds were carefully observed for 30 days. We believe that all these procedures were necessary extrinsic factors.

Ultimately, we carried out our experiments under the conclusions:

(1) The diabetic foot would not appear until the rats were feed for six to eight months.

(2) Blood glucose level of diabetic rats can be control under a certain margin of $20-25 \mathrm{mmol} / \mathrm{lit}$ by using $3.4 \mathrm{u}$ of mixed insulin per day. This procedure would prevent acute and chronic complications and extend the lifetime of rats which ultimately contribute to the establishment of an effective diabetic foot model.

(3) As diabetic rats were exposed to a prolonged period hyperglycemia, most of these rats were prone to develop solute diuresis. This would lead to dehydration and electrolyte imbalance and ultimately resulted in high mortality. Therefore additional $\mathrm{Na}^{+}, \mathrm{K}^{+}$, $\mathrm{Cl}^{-}, \mathrm{Mg}^{2+}$ in the drinking water might be crucial to prevent such complications and to extend the lifetime of rats.

(4) Diabetic rats were prone to infection because of decrease immunity as a result of prolong exposure to hyperglycemic state. So early detection of potential infection by routine daily follows up of skin infections, temperature, Pyuria, stool, pus and mucus secretions is crucial. An early detention of such incidence and adequate therapy would be helpful to reduce the mortality.

(5) In our study rats in foot scalded group (group A) Table 3, bilateral popliteal artery ligation group (group B) Table 4 and foot scalded plus popliteal artery ligation group (group C) Table 5 respectively showed mild, moderate and worst nail discoloration, degree of muscular atrophy, temperature of foot and size of ulcer. 
Citation: Han H, Liu Y, Chowdhury ATMM, Alam S (2015) Diabetic Feet Scald with Popliteal Artery Ligation - A New Study Rat Model, Represent Human Diabetic Foot Ulceration. J Mol Genet Med 9: 149. doi:10.4172/1747-0862.1000149

Page 5 of 5

The above results clearly indicated that the method in foot scalded plus artery ligation group is superior to the other two methods using scalding alone or bilateral popliteal artery ligation alone. This further suggest that the foot scalded plus artery ligation could be a suitable method to generate a diabetic foot model close to the human disease conditions and fit for the requirements of basic research and drug development. We expect that this method will provide a new tool by which research and treatment of diabetic foot may be carried out in future.

\section{Conclusion}

The experimental results shown by the "diabetic foot scalded plus popliteal artery ligation group" rats most closely resemble the symptoms of the human diabetic foot in our study. This model not only represents the diabetic state but also presents the advance changes in vascular complication (Atherosclerosis) in diabetes. We believe this model will play a role in accuracy and be helpful for the study of "Human diabetic foot ulceration". Though further study might be require to develop a superior format of this model.

\section{References}

1. Szkudelski T (2001) The mechanism of alloxan and streptozotocin action in B cells of the rat pancreas. Physiol Res 50: 537-546.

2. Ueno Y, Koike H, Annoh S, Nishio S (1996) Effects of beraprost sodium, a prostacyclin analogue, on tail flick response in two models of diabeticneuropathy in rats and its mechanism. Life Sci 59: PL105-110.

3. Boulton AJ, Kirsner RS, Vileikyte L (2004) Clinical practice. Neuropathic diabetic foot ulcers. N Engl J Med 351: 48-55.

4. Lipsky BA, Pecoraro RE, Wheat LJ (1990) The diabetic foot. Soft tissue and bone infection. Infect Dis Clin North Am 4: 409-432.

5. Shaohua Song, Lisheng He, Yan Jin (2004) Pig model of diabetic skin ulcer Experimental Research. China Clinical Rehabilitation 8: 8217-8219.
6. Qunli Chen, Wubiao Yang, Lingjun Ma (2004) Experimental rat model of diabetic foot. Journal of Henan Preventive Medicine 15: 1.

7. Rich J, Lee JC (2005) The pathogenesis of Staphylococcus aureus infection in the diabetic NOD mouse. Diabetes 54: 2904-2910.

8. Goss JR, Goins WF, Lacomis D, Mata M, Glorioso JC, et al. (2002) Herpes simplex-mediated gene transfer of nerve growth factor protects against peripheral neuropathy in streptozotocin-induced diabetes in the mouse. Diabetes 51: 2227-2232.

9. Masaki I, Yonemitsu Y, Yamashita A, Sata S, Tanii M, et al. (2002) Angiogenic gene therapy for experimental critical limb ischemia: acceleration of limb loss by overexpression of vascular endothelial growth factor 165 but not of fibroblast growth factor-2. Circ Res 90: 966-973.

10. Onimaru M, Yonemitsu Y, Tanii M, Nakagawa K, Masaki I, et al. (2002) Fibroblast growth factor-2 gene transfer can stimulate hepatocyte growth factor expression irrespective of hypoxia-mediated downregulation in ischemic limbs. Circ Res 91: 923-930.

11. Tanii M, Yonemitsu Y, Fujii T, Shikada Y, Kohno R, et al. (2006) Diabetic microangiopathy in ischemic limb is a disease of disturbance of the platelet-derived growth factor- $\mathrm{BB} /$ protein kinase $\mathrm{C}$ axis but not of impaired expression of angiogenic factors. Circ Res 98: 55-62.

12. Ebrahimian TG, Tamarat R, Clergue M, Duriez M, Levy BI, et al. (2005) Dual effect of angiotensin-converting enzyme inhibition on angiogenesis in type 1 diabetic mice. Arterioscler Thromb Vasc Biol 25: 65-70.

13. Kale B, Yüksel F, Celiköz B, Sirvanci S, Ergün O, et al. (2003) Effect of various nerve decompression procedures on the functions of distal limbs in streptozotocin-induced diabetic rats: further optimism in diabetic neuropathy. Plast Reconstr Surg 111: 2265-2272.

14. Orchard TJ, Strandness DE Jr (1993) Assessment of peripheral vascular disease in diabetes. Report and recommendations of an International Workshop sponsored by the American Heart Association and the American Diabetes Association 18-20 September 199, New Orleans, Louisiana. J Am Podiatr Med Assoc 83: 685-695.

15. Jing Chen (2007) Color Doppler ultrasound in diagnosis of lower extremities of diabetic vascular lesions. Guangxi Medicine 29: 48-49. 